\title{
Several Key Problems Related with the Commissioning and Operation of Crude Oil Tank Farm in Sino-Myanmar Pipeline
}

\author{
Jian Cai ${ }^{1,3}$, Li Ren ${ }^{2,4}$, Yuntao Bai ${ }^{1,5}$ \\ ${ }^{1}$ CNPC South-East Asia Pipeline Company Limited, Beijing, China \\ ${ }^{2}$ Sinochem Zhuhai Petrochemical Terminal Co. Ltd., Zhuhai, China \\ ${ }^{3}$ Department of Oil and Gas Storage and Transportation Engineering, China University of Petroleum (Beijing), Beijing, China \\ ${ }^{4}$ Department of Oil and Gas Storage and Transportation Engineering, Liaoning Shihua University, Fushun, China \\ ${ }^{5}$ Department of Process Equipment \& Control Engineering, Liaoning Shihua University, Fushun, China
}

Email address:

cjpipeline@163.com (Jian Cai), renli@sinochem.com (Li Ren), 446609byt@163.com (Yuntao Bai)

\section{To cite this article:}

Jian Cai, Li Ren, Yuntao Bai. Several Key Problems Related with the Commissioning and Operation of Crude Oil Tank Farm in Sino-Myanmar Pipeline. International Journal of Oil, Gas and Coal Engineering. Vol. 6, No. 5, 2018, pp. 116-119. doi: 10.11648/j.ogce.20180605.16

Received: June 5, 2018; Accepted: July 4, 2018; Published: September 27, 2018

\begin{abstract}
The Maday Island in the southwest of Myanmar is faced with the difficulties of poor natural conditions and deficient social support resources, so the requirements on the commissioning and operation of Maday Island crude oil tank farm in the Sino-Myanmar Pipeline are quite strict. In this paper, the key problems involved in the commissioning preparation and process of crude oil tank farm were summarized, including emergency material preparation, equipment check in the tank farm and safe commissioning plan. Then, the shortages of equipment selection, material selection and construction process during the operation of crude oil tank farm were analyzed. And finally, the optimization measures were put forward correspondingly. The practical experience provides the best reference and instruction for the design, construction and operation of subsequent projects of the same type.
\end{abstract}

Keywords: Sino-Myanmar Pipeline, Crude Oil Tank Farm, Isolated Island, Commissioning, Operation, Optimization

\section{Introduction}

As a demonstrated project of the Belt and Road Initiative construction, the Sino-Myanmar Crude Oil Pipeline opened up the fourth crude oil importing channel of China and was seen as a model of business cooperation between China and Myanmar. Compared with detouring in the Strait of Malacca, the Sino-Myanmar Crude Oil Pipeline shortened a transportation mileage of $1820 \mathrm{n}$ miles $(1 \mathrm{n}$ mile $=1.852 \mathrm{~km})$, therefore lowered transportation risk and cost. The pipeline crossed large rivers for many times and possessed the characteristics of big fall, high pressure, numerable u-tubes and high operation control difficulty, as a result, served as one of the most complicated liquid pipelines in the world. Among it, Maday Island crude oil tank farm of the Sino-Myanmar Pipeline locates on a small island in South-West Myanmar, and the natural conditions and society dependence of it are poor. Once accident happens, repair process could be very hard to conduct. During the commissioning preparation, development and operation of the Maday Island crude oil tank farm in the Sino-Myanmar Pipeline, key technology research was conducted based on design standard, construction demands, materials and equipments selection, and its experience provided reference for the design, construction, commissioning and operation of subsequent projects of the same type.

\section{Commissioning Preparation}

For assuring the success of Maday Island crude oil tank farm commissioning in the Sino-Myanmar Pipeline, several commissioning preparation work were done as follow [1-7]: 1 . single equipment debugging, debugged systematically in accordance with the associated regulations, made sure the integrity of the equipment and system, and their standby condition; 2. writing and reporting of the commissioning plan, storage tanks registration and tank volume calibration, wrote commissioning maneuvers script, conducted actual 
maneuvers and desktop maneuvers, normalized the operation order issuing, made sure commissioning work was procedural; 3. conducted safety check before starting, conducted function check for each equipment (especially the big tank attachments, made sure the commissioning went in accordance with procedures (regulations); 4. in overseas commissioning, the resources' availability was quite important, including the commissioning organization, operation control crew, professional engineers, maintenance crew etc., contingency device and related spare parts; 5. contingency plans and contingency maneuvers were prepared well, made sure the contingency reaction in commissioning; 6. fixed fire system, fire and gas system and oily sewage treatment system went on pilot run, and put into operation; 7. thunder and lightning protection and anti-static protection of the oil tanks passed test, went through special acceptance.

In commissioning preparation, three problems needed to be focused: 1. prepared the contingency plans and contingency maneuvers of accidents with high probability in commissioning in advance, such as oil tank buoyancy module jam, oil leakage after buoyancy module floated, oil tank leakage, oil tank overflowed and buoyancy module sinking etc. 2. in order to avoid static hazard and buoyancy module starting fault, before buoyancy module floated, according to Q/SY GD 0040.1-2011 «Vertical Cylinder Type Steel Wielding Oil Tank Operation and Maintenance Regulation», calculated crude oil feeding speed, strictly controlled the buoyancy module floated at a speed less than $0.3 \mathrm{~m} / \mathrm{h}$ when oil in for the first time. Opened the feeding valve slowly when the oil in, before the intake and output pipes were submerged, the flow speed of the intake pipe should be controlled within $1 \mathrm{~m} / \mathrm{s}$, after being submerged, the speed should be within $3 \mathrm{~m} / \mathrm{s}$, for preventing static charge from accumulating. Stopped the oil-taking after buoyancy module floated, checked the leaking condition of buoyancy module carefully. 3. Checking on site was essential, especially the interior of oil tank, the cleaning of central drainage line sump pits, float valves (one-way valve) had no jam, no debris on escalator rails, escalator rotated swiftly, sealing device worked normally, the intake and output pipes and bypass quakeproof metal flexible pipes of oil tanks connected stably, the adjustment of expansion joint adjusting pod should be in accordance with regulation and a reasonable margin should be left, buoyancy module guide device had no jam, at the same time, checked the sealing condition of manholes, loopholes, cleaning holes of oil tanks and functions of oil tank attachments.

\section{Main Problems in Commissioning}

Several abnormal conditions occurred in the Sino-Myanmar Pipeline Maday Island crude oil tank farm commissioning, and some of them were handled immediately [8-14]: 1. strictly conducted the commissioning according to commissioning plans and maneuvers, ensured the commissioning course was procedural and normalized; 2 . strictly controlled the oil-taking speed according to Q/SY GD 0040.1-2011 regulation, randomly increased the oil-taking speed in commissioning was prohibited; 3. unobstructed communication between crude oil tank farm and crude oil port should be guaranteed, and guaranteed the tank farm dispatchers' communication was a priority; 4. ensured the HSE management during the buoyancy module leakage check when oil-taking stopped; 5 . guaranteed the adjusted liquid level switches and liquid level meters worked normally in the development of oil-taking; 6 . if bias flow occurred and leaded to oil-taking in single one tank instead of in multi tanks, this problem could be fixed by adjusting the valve opening in the valve block; 7 . in commissioning, if the attachments of the oil tanks leaked and combustible gas detector alarmed due to oil-gas concentration passed the standard, the usage of the anti-explosion device and fire control measures should be paid close attention to.

\section{Operation Optimization}

\subsection{Process Equipment Optimization}

(1) Improving the equipment's IP water and dust prevention grade, and controlling the installing quality strictly; the rainfall was huge and last for long time in the Myanmar Maday Island, annual rainfall could be $5000 \mathrm{~mm}$, and last for almost half a year. By now, according to the condition of The Maday Island crude oil tank farm operation in the Sino-Myanmar Pipeline, some electric valve actuators, outdoor detecting units of fire and gas systems, control device all had burned to varying degrees. By checking the electric instrument on site, water inflow was found to be the reason. As a result, the selection of outdoor or half-outdoor installing electric instrument and other device should consider to gain water prevention grade, and water prevention grade and dust prevention grade should select grade 8 and grade 6 respectively; meanwhile, strictly controlled the wiring quality of the electric instrument etc., ensured the water prevention and dust prevention connectors of device were not damaged when being installed, water prevention and dust prevention performances reached design requirement.

(2) Improving equipment protection standard. In The Maday Island, temperature and humidity were high, annual average temperature was above $30^{\circ} \mathrm{C}$, and average humidity was above $80 \%$, in tank farm, because of the high temperature and humidity among equipment, the longevity and operation of equipment were all affected. As a result, adding some air conditioners with dehumidification function in cathodic protection device room and distribution room etc., for guaranteeing the moderate temperature and humidity.

(3) Adding suitable equipment and attachments [13-14]. In rainy season, patrolling the oil tanks was risky, consequently, tank farm monitoring device were added to inspect the safety condition on the top of tank; Sino-Myanmar Pipeline Maday Island crude oil tank water cutter's inlet valve selected wedge gate valve in design, however, because the sealing of wedge gate valve was not good, valve leakage occurred after commissioning, hence replaced them with ball valves that had better sealing function and higher price.

(4) Optimizing foam extinguishing system [15]. In the 
original design plan of Maday Island crude oil tank farm in the Sino-Myanmar Pipeline, the foam station of low-expansion foam fire extinguishing system adopted gear foam pumps driven by two motors, one in use and one for standby, gear foam pump motors were all supplied by The Maday Island power generating system, once problem occurred in power generating system or station stayed in ESD condition, the generators gas skid will cut the gas supply, resulting in all the generators stop and foam pumps in foam station couldn't start. So, foam skid were replaced with water turbine driven style or pressured foam proportioning device, both of them don't need to be driven by external power. At the same time, the foam skid driven by electricity and diesel could be considered too, for guaranteeing the foam extinguishing system emergency availability.

\subsection{Material Optimization}

(1) Materials selection of equipment and device [16-18]. The Myanmar Maday Island area had high temperature, humidity and rainfall, and normally the material of extinguishing water pipe flange gasket was ordinary rubber mat, which aged fast and easily being damaged, if maintenance needed to be operated on high place, the risk, workload and difficulty could be great, therefore the rubber ones were replaced with the metal gaskets that had better longevity and quality. In addition, selecting pitch anticorrosion material for central drainage pipeline sump pits on top of the crude oil tanks was not suitable for The Maday Island's climate, and that was because the pitch anticorrosion materials in central sump pits were all flushed away through the drainage pipelines by rain. As a result, sealing and anticorrosion materials had heat resistance and humidity resistance should be selected for this part.

(2) Anticorrosion construction process control [19-21]. The Maday Island stayed in an environment of salt spray, moisture, strong rainfall, high temperature and humidity, and in this area, the atmosphere contained vapor, oxygen, nitrogen, carbon dioxide, sulfur dioxide, chloride and sulfate suspending among it, also the rain water was alkaline. Compared with common atmosphere, it had higher humidity, salinity, strong alkalinity, high temperature and obvious wetting-drying circles effect, complicated corruptive environment, so except that tanks anticorrosion process should be similar with ocean platform equipment in ocean atmosphere, other factors should also be taken into consideration. In the original design plan of The Maday Island crude oil tank farm in the Sino-Myanmar Pipeline, 3E anticorrosion material, namely epoxy zinc rich primer + epoxy micaceous iron oxide intermediate coatings + fluorocarbon coatings were adopted on the outer wall of tanks and on top of buoyancy module. Although the effect of The Maday Island's coastal salt spray corruption was taken into fully consideration, however after 2 years, partial corruption occurred on tanks' surface. Through on-site analysis, undemanding construction process and quality control could be the reasons of anticorrosion coatings' failure. In addition, further analysis about the anticorrosion process of tanks of the same type in this area should be conducted and perfect anticorrosion measures should be adopted.

\subsection{Equipment and Facilities Optimization}

According to the physical property of crude oil that the Sino-Myanmar Crude Oil Pipeline transported and local natural conditions etc., in accordance with the principle of reducing the costs and increasing the benefits, and considering the tank farm's actual operation, increasing and reducing some equipment and facilities in design at discretion [22-25].

(1) Adding electric actuators design for drainage valves and oily water control valves in drainage valve well outside the tank farm fire dike. In the original design plan of The Maday Island crude oil tank farm in the Sino-Myanmar Pipeline, this part was manual operation, due to The Maday Island's long rainy season and high rainfall frequency, constantly open and close the drainage valves manually in the valve well was not convenient for operators, by now, during spilled oil pool build-out, electric actuators-driven drainage valves were added.

(2) Increasing the quantity of production and security CCTV (Closed Circuit Television) monitoring camera. In the original design plan of The Maday Island crude oil tank farm in the Sino-Myanmar Pipeline, CCTV (Closed Circuit Television) monitoring cameras were arranged in some areas, but not in some important production parts ( tank's buoyancy module in tank farm, fire pump chamber, generator chamber etc.). Because the oil reservoir is within the range of important production and key safety production place, guaranteeing the equipment's safety and security was especially important, therefore the quantity of CCTV (Closed Circuit Television) monitoring camera should be added.

\subsection{Enhancing Design and Equipment Authentication Standard}

The fixed fire system of The Maday Island crude oil tank farm in the Sino-Myanmar Pipeline adopted GB 50183-2015 «Petroleum and Gas Engineering Design Fire Fighting Regulation», and quality authentication standard of fire pumps and associated equipment adopted CCCF (China Certification Center for Fire Products Ministry of Public Security) compulsory certification. Compared with other overseas international pipeline engineering construction, conducting fire design and equipment procurement in accordance with the standards above was insufficient, which was expressed in incomplete fire protection coverage of fixed fire system, high equipment failure rate, and difficult equipment debugging. The fixed fire system of certain overseas pipeline engineering was designed by NFPA 15-2012 «Fixed Fire Sprinkler System Standard». Among it, fire sprinkler system was designed in fire pump chamber, foam stations, generator chamber, main pump area and feeding pump area, and main fire and associated equipment adopted UL/FM authentication standard, which had good function and reliability. A super oil depot of $120 \times 10^{4} \mathrm{~m}^{3}$ overall design capacity could be seen as a significant hazard, therefore the importance of fire system was self-evident. Hence from the perspective of safe operation, 
international oil and gas engineering of this type should enhance the standard of design and equipment authentication.

\section{Conclusion}

The Maday Island crude oil tank farm in the Sino-Myanmar Pipeline located in an oceanic environment of high humidity and temperature, was faced with problems like goods supply difficulty, technique support insufficient etc., and many technical problems existed in commissioning preparation, commissioning and operation, therefore analyzing key problems at different phases, proposing corresponding solutions, providing important technique and theory support for crude oil tank farm design, construction and operation management staff of the same type in the future, contributing to energy conservation and efficiency and safe operation of tank farm.

\section{References}

[1] New progress in relevant technology research of oil\& gas storage and transportation in China [J]. Oil \& Gas Storage and Transportation, 2012, 31 (1):1-7.

[2] Experiences and revelations gained from the construction of Tank farm for oil storage and transportation abroad [J]. Oil \& Gas Storage and Transportation, 2012, 31 (2):92-95.

[3] Leak analysis of drainage pipe for outward floating roof tank [J]. Oil \& Gas Storage and Transportation, 2002, 21 (7):54-56.

[4] The application of lifting technology of pontoon's center stand in oil tank [J]. Oil \& Gas Storage and Transportation, 2005, 24 (11):48-49.

[5] Application of ASME B31 in the construction of oil field surface engineering abroad [J]. Oil \& Gas Storage and Transportation, 2011, 30 (12):927-934.

[6] Advanced standards for the fire dike construction of storage tank in North America and Russia [J]. Oil \& Gas Storage and Transportation, 2016, 35 (2):203-207.

[7] Radon concentration in oily sludge produced from oil refineries in the southern oil plant at Basra Governorate-Iraq [J]. Archives of Applied Science Research, 2011, 3 (6):263-271.

[8] Numerical simulation of hazardous areas at loading of oil tank [J]. Oil \& Gas Storage and Transportation, 2015, 34 (1):53-56.

[9] Source and prevention of static electricity in pump station [J]. Oil \& Gas Storage and Transportation, 2015, 34 (2):180-182.
[10] Exploring reasons for tank oil-overs and solution $\mathrm{s}[\mathrm{J}]$. Oil Depot and Gas Station, 2006, 15 (4):35-37.

[11] Risk analysis of pool fire in oil depot area [J]. Petro \& Chemical Equipment, 2011, 14 (6):48-51.

[12] Considerations on a fire and explosion accident at Buncefield oil storage depot in England [J]. Petrochemical Safety and Environmental Protection Technology, 2009, 25 (6):45-48.

[13] Fine design on the process flow of oil depot [J]. Guangzhou Chemical Industry, 2013, 41 (3):117-118.

[14] Safety design of tank area for large scale oil depot [J]. Oil-Gas field Surface Engineering, 2011, 30 (8):53-54.

[15] Calculation to foam volume of floating roof oil tank [J]. Oil \& Gas Storage and Transportation, 2008, 27 (1):51-54.

[16] Corrosion and anticorrosion technology in offshore platforms [J]. China Offshore Platform, 2008, 23 (6):39-42.

[17] Risk status and necessity of RBI for offshore ASTs in China [J]. Oil \& Gas Storage and Transportation, 2015, 34 (1):8-14.

[18] The application of nano-titanium polymer dope in the storage oil jar [J]. Total Corrosion Control, 2005, 19 (4):12-18.

[19] Feasibility study on pressure testing with seawater for tank repair [J]. Oil \& Gas Storage and Transportation, 2006, 25 (9):55-57.

[20] National Fire Protection Association. Recommended practice for handling releases of flammable and combustible liquids: NFPA 329-2005 [S]. Quincy: National Fire Protection Association, 2005:7-9.

[21] Offshore service specification-Risk based verification: DNV-OSS-300 [S]. Oslo: DNV, 2004:3-6.

[22] Multi-objective decision making for layout of crude oil tank farms based on the method of ideal outranking cardinal point [J]. Safety and Environmental Engineering, 2016, 23 (2):66-70, 74.

[23] Key points analysis of safety assessment of hazardous chemicals in oil tank area of oil field station and oil field [J]. Petrochemical Safety and Environmental Protection Technology, 2017, 33 (1):34-36.

[24] Analysis the effects on the China-Myanmar Crude Oil Pipeline induced changes in import crude oil shipping costs [J]. Mathematics in Practice and Theory, 2014, 44 (18):44-52.

[25] Study on a kind of oil transportation job scheduling optimization system in crude oil depot [J]. Computers and Applied Chemistry, 2017, 34 (2):140-144. 